\section{References}

1. Okada Y, Nasu M, Takahashi Y, Handa N, Fujiwara H, Shinkai M, et al. Late results of mitral valve repair for mitral regurgitation. Jpn J Thorac Cardiovasc Surg. 2003;51:282-8.

2. Rankin JS, Orozco RE, Addai TR, Rodgers TL, Tuttle RH, Shaw LK, et al. Several new considerations in mitral valve repair. J Heart Valve Dis. 2004;13:399-409.
3. David TE, Omran A, Armstrong S, Sun Z, Ivanov J. Long-term results of mitral valve repair for myxomatous disease with and without chordal replacement with expanded polytetrafluoroethylene sutures. $J$ Thorac Cardiovasc Surg. 1998;115:1279-85.

4. Adams DH, Kadner A, Chen RH. Artificial mitral valve chordae replacement made simple. Ann Thorac Surg. 2001;71:1377-8.

5. Sakihara H. Sakihara-type deep vascular ligation apparatus. Surg Today. 1997;27:680-1.

\title{
How to avoid traction to a pedicled internal thoracic artery graft
}

\author{
Franziska H. Bernet, MD, Martin T. R. Grapow, MD, and \\ Hans-Reinhard Zerkowski, MD, FETCS, Basel, Switzerland
}

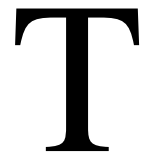

he left internal thoracic artery (LITA) is the most important conduit for coronary artery bypass grafting. ${ }^{1}$ Its application is an independent predictor of late survival, and therefore the LITA should be used in almost all patients. ${ }^{2}$ However, which harvesting technique has more advantages is still unclear. ${ }^{3,4}$ In our institution we routinely performed pedicled LITA grafting to avoid deprivation of the vaso vasorum, innervation and lymphatic and venous drainage.

We present our experience with a technique, first described in 1997 by Rao and colleagues, ${ }^{5}$ to perform a tension-free LITA graft to the left anterior descending artery (LAD).

\section{Technique}

The coronary artery bypass grafting procedure is carried out under standardized conditions concerning surgical management delivery of anesthesia. As usual, we graft the LAD with the pedicled LITA. Before completion of the distal anastomosis, the pericardium is divided with an inversed $\mathrm{T}$-shaped slit to enable a tension-free position of the graft. In case of traction caused by hyperinflated lungs, we additionally create a slit in the apical segment of the upper lobe during arrested ventilation by using an Endo GIA Universal stapler (Autosuture; Tyco Healthcare, Mansfield, Mass) with a double-breasted self-cutting clip suture of 45 or $60 \mathrm{~mm}$ in length. The deflated lung is stabilized with 2 atraumatic clamps, allowing a gentle traction toward the surgeon. The stapler is preliminarily stretched between these 2

\footnotetext{
From the Division of Cardiothoracic Surgery, University Hospital Basel, Basel, Switzerland,

Received for publication Oct 4, 2004; accepted for publication Oct 12, 2004.

Address for reprints: Franziska Bernet, MD, Division of Cardio-Thoracic Surgery, University Hospital Basel, Spitalstrasse 21, 4031 Basel, Switzerland (E-mail: bernetf@uhbs.ch).

J Thorac Cardiovasc Surg 2005;129:1186-7

$0022-5223 / \$ 30.00$

Copyright $\odot 2005$ by The American Association for Thoracic Surgery doi:10.1016/j.jtcvs.2004.10.013
}

clamps, and after verifying the correct position, the cut is released. After restarting ventilation and weaning from cardiopulmonary bypass, the

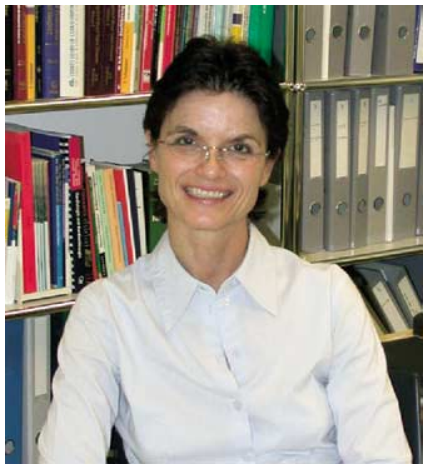

Dr Bernet pedicled LITA conduit is run through the resulting fissure and disappears inside the slit, lying in a straight line to the LAD without kinking (Figure 1). Between 2000 and 2003, 35 (2.4\%) of 1451 patients undergoing isolated coronary artery bypass surgery were treated with the above technique. Eighty percent $(n=28)$ of these patients had a history of severe chronic obstructive pulmonary disease with emphysema. All patients had an uneventful intraoperative and postoperative course. No history of persistent pulmonary

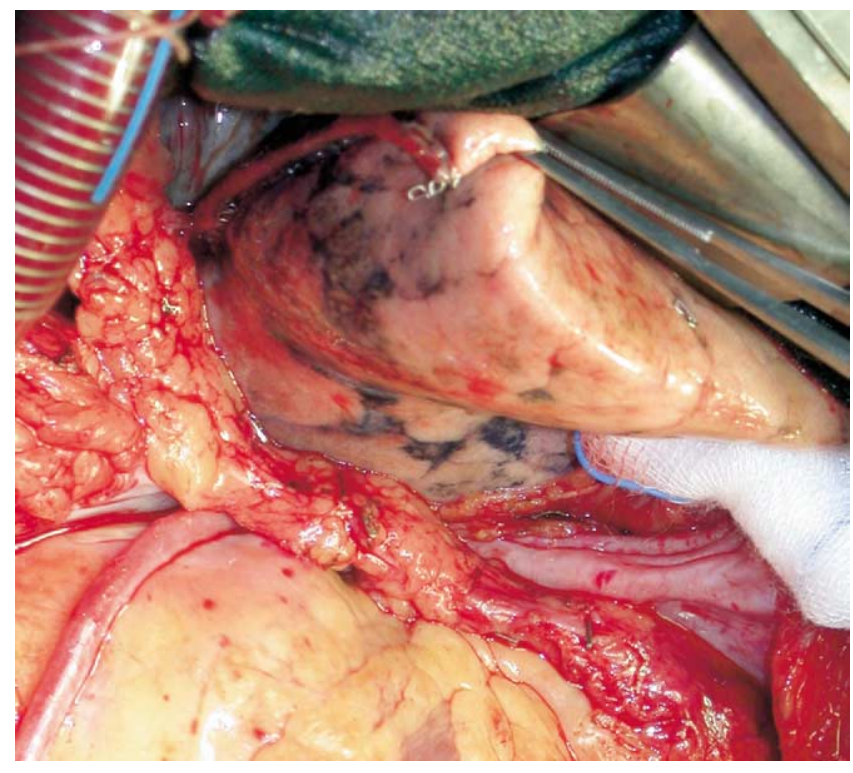

Figure 1. After restarting ventilation, the pedicled LITA is running in a straight line through the fissure of the slit upper lung lobe. 
leakage or prolonged respiratory support was observed nor did major bleeding, mediastinitis or empyema occur.

\section{Discussion \\ The slitting of the left upper pulmonary lobe is an easy and effective method to avoid traction to the LITA conduit and is also applicable in off-pump surgery. To arrest the ventilation during the procedure is a very useful trick, first to simplify the positioning and second to avoid injury of the inflated lung with the tip of the stapler. This technique is also applicable on the right side, but until now, we have no experience as to how much graft length we could gain with a slit right lung. The main advantage of this technique is the straight,tension-free position- ing of the graft without kinking. Furthermore, in case of a redo procedure, the LITA graft is protected underneath the lung and is far away from the track of the sternotomy. However, a disadvantage is represented by the costs in connection with the single-used disposable device. The costs for the device and the clip suture amount to approximately $\$ 250$ US. A possible pitfall}

might be in patients with multiple apical bullae. A single slit could result in persisting air leaks caused by the possibility of torn tissue. If the patient fulfills the criteria of lung volume reduction surgery, a more extended procedure with resection of the upper segments or a bullectomy could be performed.

\section{References}

1. Cameron A, David KB, Green G, Schaff HV. Coronary bypass surgery with internal thoracic artery grafts-effects on survival over a 15-year period. N Engl J Med. 1996;334:216-9.

2. Hirotani T, Nakamichi T, Munakata M, Takeuchi S. Risks and benefits of bilateral internal thoracic artery grafting in diabetic patients. Ann Thorac Surg. 2003;76:2017-20.

3. Gaudino M, Toesca A, Nori SL, Glieca F, Possati G. Effect of skeletonization of the internal thoracic artery on vessel wall integrity. Ann Thorac Surg. 1999;68:1623-7.

4. Del Campo C. Pedicled or skeletonized? A review of the internal thoracic artery graft. Tex Heart Inst. 2003;30:170-5.

5. Rao P, Natarajan K, Morritt G. "LIMA fissure" for a tension-free IMA graft in emphysema. Ann Thorac Surg. 1997;63:561-2.

\title{
Closure of ventricular septal defects in the donor heart before transplantation: Toward expanded acceptance criteria
}

\author{
S. Maltais, MD, MSc, ${ }^{a, b, c}$ M. Carrier, MD, ${ }^{a, b, c}$ M. Pellerin, $M D^{a, b, c}$ and \\ L. P. Perrault, MD, PhD, a,b,c Montreal, Quebec, Canada
}

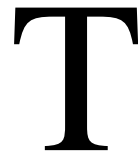

he limited supply and increasing shortage of adequate donor organs for transplantation has been met with expansion of criteria for donor heart acceptance. ${ }^{1}$

Patent foramen ovale and atrial septal defects have been diagnosed after cardiac transplantations $s^{2,3}$ and have been treated by surgical or transcatheter closure. ${ }^{4}$ Occasionally, significant rightto-left shunting across a septal patent foramen ovale might result in profound hypoxemia. Residual atrial defects might cause a serious hemodynamic compromise because of shunting and significant tricuspid regurgitation. ${ }^{3}$ The present report describes 2 successful

From the Research Center and the Department of Surgery, ${ }^{\mathrm{b}}$ Montreal Heart Institute, and the University of Montreal, ${ }^{\mathrm{c}}$ Montreal, Quebec, Canada.

Received for publication Aug 30, 2004; accepted for publication Sept 7, 2004.

Address for reprints: L. P. Perrault, MD, PhD, Research Center, Montreal Heart Institute, 5000 Belanger St East, Montreal, Quebec, H1T 1C8 Canada (E-mail: louis.perrault@icm-mhi.org).

J Thorac Cardiovasc Surg 2005;129:1187-8

$0022-5223 / \$ 30.00$

Copyright $\odot 2005$ by The American Association for Thoracic Surgery

doi:10.1016/j.jtcvs.2004.09.030 heart transplantations after concomitant surgical closure of a ventricular septal defect (VSD) in the donor heart.

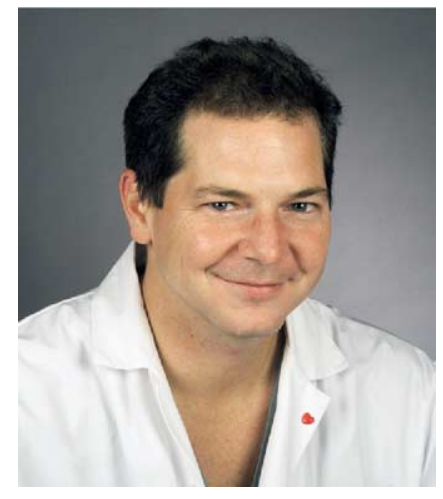

Dr Perrault

\section{Clinical Summary}

PATIENT 1. A 41-year-old man with no medical history was given a diagnosis of brain death after self-inflicted head trauma, and consent was obtained for multiple organ donation.

The preharvesting transthoracic echocardiogram revealed a small, 4-mm, restrictive perimembranous VSD with a normal ejection fraction and normal heart valves. Hemodynamic parameters were completely normal without need for pharmacologic support.

A compatible 58-year-old male recipient with terminal idiopathic dilated cardiomyopathy was identified at our institution.

The donor heart was explanted through a median sternotomy, and cardiac arrest was induced with $1 \mathrm{~L}$ of Celsior solution (Sangstat, Montreal, Quebec, Canada) at $4{ }^{\circ} \mathrm{C}$ along with surface cooling. Before transplantation, the VSD was repaired on the back table through a 4-cm right anterior ventriculotomy. Two interrupted polypropylene 4-0 sutures were used for closure of the defect (Figure 1, A). A standard orthotopic heart transplantation with biatrial anastomotic implantation (Stanford technique) was then performed with an ischemic time of 106 minutes. The pa- 